\title{
PENGENALAN KONSENTRASI WARNA PELUMAS MENGGUNAKAN WEBCAM
}

\author{
Winarno $^{1}$, Deny Arifianto ${ }^{2}$, Sisca D N Nahdliyah ${ }^{3}$, M Z Pratama ${ }^{4}$, R A Nuswantari ${ }^{5}$ \\ ${ }^{1,2,3)}$ Dosen Fakultas Vokasi, Universitas Airlangga \\ Jl. Dharmawangsa Dalam No. 28-30 (Kampus B) Surabaya \\ ${ }^{1}$ winarnoefst.unair.ac.id \\ 2deny-a@fst.unair.ac.id \\ ${ }^{3}$ sisca-dina-nur-nevokasi.unair.ac.id \\ ${ }^{4,5)}$ Mahasiswa Fakultas Vokasi, Universitas Airlangga \\ Jl. Dharmawangsa Dalam No. 28-30 (Kampus B) Surabaya \\ ${ }^{3} \mathrm{mzulkarnainpratama@gmail.com}$ \\ ${ }^{4}$ rivaardhia49@gmail.com
}

\begin{abstract}
The number of fake lubricants in Indonesia has made many people nervous. In 2008, 50\% to $60 \%$ of lubricants that already existed in Indonesia were fake, therefore carefulness was needed in choosing these lubricating products. The first step that can be done to identify fake lubricants is to recognize by its color. Therefore, this research aims to design a device that is able to recognize the color of lubricants using a webcam. The research sample is base oil with levels of red and blue, each of which is 0 ppm, $10 \mathrm{ppm}, 50 \mathrm{ppm}, 100 \mathrm{ppm}, 150 \mathrm{ppm}$, and 200 ppm. This sample is characterized by the color composition used as a reference system, then tested to identify other samples. Characterization is done by placing a sample on a cuvette and inserting it into the sample room with adequate lighting. The web camera is used to take sample pictures, then the image is analyzed based on color composition. Based on the results of tests that have been conducted, it shows that this system is able to identify $100 \%$ lubricant samples correctly. These results indicate that it is very possible to develop an early detection method for lubricating oil based on the composition of the colors using a webcam.
\end{abstract}

Keywords - lubricant, color compositions, webcam.

\section{Pendahuluan}

Sebanyak 50\% hingga 60\% atau lebih dari separuh pelumas/oli yang beredar di Indonesia terbukti palsu [1]. Fakta ini menunjukkan bahwa peredaran pelumas palsu di Indonesia tergolong tinggi, sehingga konsumen harus lebih berhati-hati ketika ketika membeli pelumas. Hingga tahun 2017 tingkat pembajakan atau pemalsuan di Indonesia tidak kunjung turun [2]. Pemalsuan pelumas dilakukan pada semua merek baik itu produksi dalam negeri maupun luar negeri. Solusi yang ditawarkan oleh konsultan agar konsumen yakin bahwa pelumas yang dibeli adalah asli yaitu dengan membeli di distributor yang memiliki otoritas resmi.

Pelumas berfungsi untuk mencegah atau mengurangi keausan dan gesekan antara permukaan dua logam [6], selain itu juga berfungsi sebagai pendingin, peredam getaran dan mengangkut kotoran pada motor bakar. Minyak pelumas alam (mineral oil) diperoleh dari bahan tambang minyak mentah (crude oil) yang komposisinya terdiri dari Alkana (hidrokarbon jenuh) atau sering disebut parafin, Alkena (hidrokarbon tak jenuh), hidrokarbon aromatic dan senyawa lain dengan persentase kecil [4].

Pelumas banyak macamnya dan memiliki fungsi yang berbeda-beda, sehingga komposisi antara pelumas satu dengan lainnya tidaklah sama. Beberapa macam pelumas dapat dibedakan berdasarkan warnanya. Warna minyak pelumas selain menunjukkan kemurnian dan daya tarik produk juga dapat dipakai sebagai dasar untuk mengetahui tingkat kontaminasi minyak pelumas [5]. Selain itu, warna pelumas dapat dijadikan tahapan awal dalam mengidentifikasi keaslian pelumas yang beredar di pasar lokal. Dalam produksi pelumas, standar 
pengukuran warna berdasarkan American Society for Testing and Materials (ASTM) D1500. Metode pengujian ini mencakup penentuan visual warna berbagai macam produk minyak bumi, seperti minyak pelumas, minyak pemanas, minyak solar, dan lilin minyak bumi [3].

Salah satu alat yang digunakan untuk menguji nilai intensitas warna pelumas adalah color comparator. Alat ini menggunakan sumber cahaya standar, sampel cairan ditempatkan dalam wadah uji dan dibandingkan dengan disk kaca berwarna merah, kuning dan biru yang memiliki indeks warna bernilai 0,5 - 8,0. Ketika tidak ditemukan disk kaca dengan warna yang mirip dan warna sampel jatuh antara dua warna standar, yang dilaporkan adalah warna yang lebih tinggi. Hasil dari pengujian ini dicatat sebagai ASTM color.

Berdasarkan latar belakang diatas, maka pada penelitian ini mengusulkan pembuatan prototype perangkat pengenalan konsentrasi warna pelumas menggunakan webcam. Diharapkan alat ini mampu digunakan sebagai tahap awal untuk membandingkan antara pelumas palsu dengan pelumas asli berdasarkan tingkat kemiripan warnanya, selain itu juga dapat dikembangkan menjadi color comparator untuk menentukan indeks warnanya.

\section{TinjAUAn PUSTAKa}

\section{A. Pelumas}

Pelumas adalah zat kimia, yang umumnya cairan, yang diberikan di antara dua benda bergerak untuk mengurangi gaya gesek [6]. Suatu bahan dapat dikategorikan sebagai pelumas jika mengandung bahan dasar dan paket aditif. Pelumas yang baik harus bisa membuat kinerja mesin lebih ringan dan bertugas sebagai pelindung komponen metal didalam mesin dari friksi akibat gesekan antar logam.

Dari bahan dasarnya, pelumas mesin yang umum beredar terbagi dua jenis, yaitu:

1. Pelumas Mineral (Base Oil) diperoleh dari hasil tambang minyak bumi yang diolah menjadi pelumas dan ditambah bahan aditif untuk menambah mutu pelumas menjadi lebih baik.

2. Pelumas Sintetis (Synthetic Oil) terdiri atas Polyalphaolifins senyawa ini kemudian dicampur dengan pelumas mineral. Pada dasarnya, pelumas sintetis didesain untuk menghasilkan kinerja yang lebih efektif dibandingkan dengan pelumas mineral.

Pada umumnya pelumas yang beredar pasar lokal memiliki warna yang khas, hal ini yang membedakan antara pelumas merek satu dengan yang lainnya.
Warna minyak pelumas selain menunjukkan kemurnian dan daya tarik produk juga dapat dipakai sebagai dasar untuk mengetahui tingkat kontaminasi minyak pelumas [5]. Warna bertindak sebagai indikasi dan tingkat kemurnian bahan, dimana bila kisaran warna produk diketahui maka variasi diluar kisaran yang ditentukan dapat merupakan indikasi kemungkinan terkontaminasi dengan produk lain. Warna menunjukkan terang gelapnya suatu minyak pelumas yang diukur dari intensitas cahaya yang dapat menembus sejumlah minyak tertentu.

\section{B. Interaksi Cahaya dan Materi}

Cahaya adalah suatu bentuk energi radiasi yang mempunyai sifat sebagai gelombang dan partikel. Sifatnya sebagai gelombang dapat dilihat dengan terjadinya pembiasan dan pemantulan cahaya oleh suatu medium, sedangkan sifatnya sebagai partikel dapat dilihat dengan terjadinya efek foto listrik. Beberapa parameter yang terlibat untuk menentukan sifat optik benda adalah reflektans (sifat pemantulan, absorbans (sifat penyerapan) dan transmitans (sifat penerusan). Adanya perubahan warna menyebabkan kemampuan penerusan dan pemantulan dari produk juga berubah. Variasi warna adalah bentuk variasi panjang gelombang radiasi elektromagnetik. Suatu bahan akan menyerap atau memantulkan sinar dengan berbagai panjang gelombang bergantung warnanya.

Apabila cahaya (monokromatik maupun campuran) jatuh pada suatu medium homogen, sebagian dari sinar masuk akan dipantulkan, sebagian diserap dalam medium itu, dan sisanya diteruskan. Intensitas sinar yang masuk dinyatakan oleh Io, Ia intensitas sinar terserap, It intensitas terteruskan, $I r$ intensitas sinar terpantulkan, maka :

$$
I_{0}=I_{a}+I_{t}+I_{r}
$$

Hukum Lambert menyatakan bahwa bila cahaya monokromatik melewati medium tembus cahaya, laju berkurangnya intensitas oleh bertambahnya ketebalan, berbanding lurus dengan intensitas cahaya. Ini setara dengan menyatakan bahwa intensitas cahaya yang dipancarkan berkurang secara eksponensial dengan bertambahnya ketebalan medium yang menyerap atau dengan menyatakan bahwa lapisan mana pun dari medium itu tebalnya sama akan menyerap cahaya masuk kepadanya dengan fraksi yang sama.

Hukum Beer sejauh ini telah dibahas absorpsi cahaya dan transmisi cahaya untuk cahaya 
monokromatik sebagai fungsi ketebalan lapisan penyerap saja. Tetapi dalam analisa kuantitatif terutama berurusan dengan larutan. Beer mengkaji efek konsentrasi penyusun yang berwarna dalam larutan, terhadap transmisi dan konsentrasi seperti yang ditemukan Lambert antara transmisi dan ketebalan lapisan, yakni intensitas berkas cahaya monokromatik berkurang secara exponensial dengan bertambahnya konsentrasi zat penyerap secara linear.

Hubungan antara Absorbans $A$, transmitans $T$, koefisien absorpsi molar adalah:

$$
A=\log \frac{I_{0}}{I_{t}}=\log \frac{1}{T}=-\log T
$$

Dapatlah disebut bahwa untuk pengukuran kalorimetri Io biasanya ditafsirkan sebagai intensitas cahaya yang diteruskan oleh pelarut murni, atau intensitas cahaya yang memasuki larutan, $I t$ intensitas yang keluar dari alarutan, atau diteruskan oleh larutan itu [4].

\section{Model Warna RGB}

RGB adalah suatu model warna yang terdiri dari merah, hijau, dan biru, digabungkan dalam membentuk suatu susunan warna yang luas. Setiap warna dasar, misalnya merah, dapat diberi rentang-nilai. Monitor komputer, nilai rentangnya paling kecil $=0$ dan paling besar $=255$. Pilihan skala 256 ini didasarkan pada cara mengungkap 8 digit bilangan biner yang digunakan oleh mesin komputer. Dengan cara ini, akan diperoleh warna campuran sebanyak 256 x 256 x 256 $=1677726$ jenis warna.

Warna sebuah citra digital ditentukan oleh besar intensitas piksel-piksel penyusunnya. Warna ini diperoleh dari besar kecilnya intensitas cahaya yang ditangkap oleh sensor. Hasil citra digital disimpan di memori berupa nilai-nilai intensitas yang berbentuk matriks.

\section{Metode Penelitian}

Tahapan dalam melakukan penelitian ini diantaranya adalah preparasi sampel, desain peralatan (setup experiment), perancangan software, pengambilan data, karakterisasi sampel, pengujian, analisis dan pembahasan.

\section{A. Persiapan Bahan}

Proses preparasi sampel dilakukan terlebih dahulu di laboratorium Production Unit PT. PERTAMINA Lubricants Unit Gresik dan Surabaya. Bahan yang diperlukan dalam pembuatan sampel pelumas yaitu, base oil dan pewarna. Jenis warna yang digunakan adalah merah dan biru dengan komposisi masingmasing adalah $10 \mathrm{ppm}, 50 \mathrm{ppm}, 100 \mathrm{ppm}, 150 \mathrm{ppm}$, dan 200 ppm. Sampel penelitian ditunjukkan pada Gambar 1.

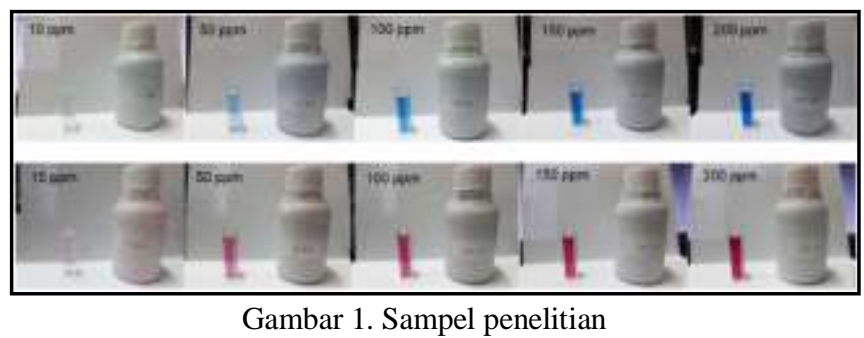

\section{B. Desain Peralatan}

Desain peralatan terdiri dari webcam, cuvette yang diisi dengan cairan sampel, sumber cahaya, dan layar. Webcam yang digunakan adalah seri AS0230, terhubung dengan komputer melalui USB port, jarak fokus $3.85 \mathrm{~mm}$, sensor gambar menggunakan CMOS ukuran 10 MP. Sumber cahaya menggunakan Light Emitting Diode (LED) array terhubung dengan power supply $12 \mathrm{~V} / 3 \mathrm{~A}$. Jenis cahayanya adalah warna putih polikromatis 3000 lux. Layar terbuat dari bahan Polylactid Acid (PLA) warna putih dengan ukuran panjang, lebar dan tebal masing-masing adalah 200 $\mathrm{mm}, 110 \mathrm{~mm}, 1.5 \mathrm{~mm}$. Cuvette terbuat dari bahan mika berukuran $12.5 \mathrm{~mm}$ x $12.5 \mathrm{~mm} \times 45 \mathrm{~mm}$ dengan volume 2,5 $\mathrm{mL}$. Peralatan tersebut dirangkai seperti pada Gambar 2.



Gambar 2. Setup experiment: A - webcam, B - cuvette, C - layar, D - sumber cahaya

\section{Perancangan Software}


Antarmuka didesain dengan menggunakan software berbasis Bahasa pemrograman Pascal. Selain sebagai antarmuka antara komputer dengan pengguna (user) juga sebagai pemroses dan penentu keputusan. Diagram alir software ditunjukkan pada Gambar 3.



Gambar 3. Diagram alir software

Pada saat software dijalankan, langkah pertama yang harus dilakukan adalah memilih sumber kamera. Jika menggunakan laptop, maka akan muncul dua pilihan kamera, yaitu kamera laptop dan webcam, sehingga yang harus dipilih adalah webcam. Program selanjutnya akan menghitung nilai rerata komposisi warna $R, G$, dan $B$ dari gambar yang ditangkap oleh webcam seperti ditunjukkan pada Persamaan 3. Ukuran gambar yang dihasilkan oleh webcam adalah 480 x 360 px, gambar tersebut kemudian dihitung rerata nilai $\mathrm{R}, \mathrm{G}$, dan B pada daerah yang berukuran 96 x 141 px seperti yang ditunjukkan pada Gambar 4.

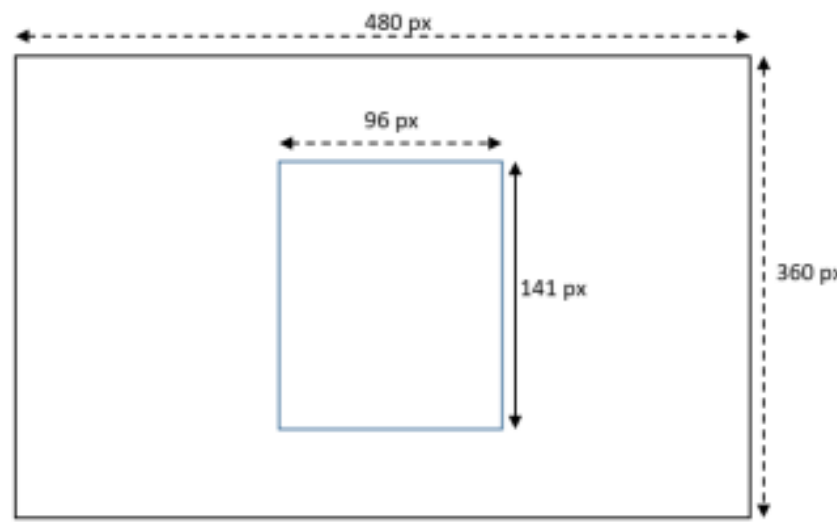

Gambar 4. Citra yang dihasilkan webcam

$$
\bar{R}=\frac{\sum R_{x, y}}{H \times W} \quad ; \bar{G}=\frac{\sum G_{x, y}}{H \times W} \quad ; \bar{B}=\frac{\sum B_{x, y}}{H \times W}
$$

Jika yang dilakukan adalah untuk mengumpulkan data, maka pada menu dapat dipilih "collecting data". Menu ini digunakan untuk mengumpulkan data dari beberapa sampel pelumas dari berbagai konsentrasi warna dalam sebuah tabel, selanjutnya data disimpan dalam format Microsoft excel. Data yang disimpan adalah nilai $R, G$, dan $B$ dari masing-masing sampel pelumas. Data ini kemudian dijadikan fitur untuk masing-masing konsentrasi warna pelumas.

Pemilihan menu "identifying" digunakan untuk mencocokkan sampel dengan data yang ada pada database, jika datanya sesuai maka akan dikenali dengan konsentrasi dan warna yang bersesuaian, demikian pula sebaliknya. Hasil pencocokan dapat disimpan dalam bentuk table dalam format Microsoft excel.

\section{HaSil Dan PEMbahasan}

Data penelitian diperoleh dengan cara menghitung nilai rerata kompoisi $R, G$, dan $B$ citra dari masingmasing sampel. Antarmuka software untuk pengambilan data ditunjukkan pada Gambar 5 .

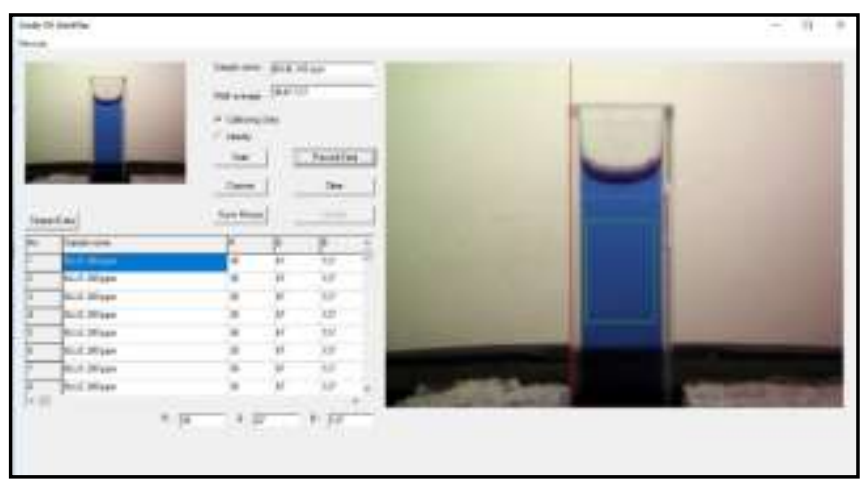


Berdasarkan hasil pengamatan diperoleh data rerata komposisi $R, G$, dan $B$ masing-masing sampel seperti yang ditunjukkan pada Tabel 1 .

TABEL I

DATA RERATA NILAI R, G, DAN B

\begin{tabular}{|c|l|c|c|c|c|}
\hline $\mathbf{n}$ & \multicolumn{1}{|c|}{ Color } & $\begin{array}{c}\text { Concentration } \\
(\mathbf{p p m})\end{array}$ & $\mathbf{R}$ & $\mathbf{G}$ & $\mathbf{B}$ \\
\hline 1 & Background & - & 189 & 178 & 170 \\
\hline 2 & No Color & 0 & 177 & 165 & 156 \\
\hline 3 & Red & 10 & 174 & 151 & 147 \\
\hline 4 & Red & 50 & 146 & 57 & 79 \\
\hline 5 & Red & 100 & 132 & 26 & 52 \\
\hline 6 & Red & 150 & 122 & 18 & 36 \\
\hline 7 & Red & 200 & 109 & 15 & 24 \\
\hline 8 & Blue & 10 & 167 & 160 & 156 \\
\hline 9 & Blue & 50 & 148 & 148 & 151 \\
\hline 10 & Blue & 100 & 78 & 105 & 141 \\
\hline 11 & Blue & 150 & 60 & 91 & 137 \\
\hline 12 & Blue & 200 & 38 & 67 & 128 \\
\hline
\end{tabular}

Gambar true color terdiri dari komposisi $R, G$ dan $B$. Pada gambar 24 bit, masing-masing komponen warna bernilai 8 bit dengan rentang nilai $0-255$. Nilai 0 pada masing-masing komponen menunjukkan warna yang pekat dan cenderung berwarna gelap, sedangkan nilai yang lebih besar menunjukkan warna akan semakin memutih, hingga maksimal 255 adalah warna putih. Tabel 1 menunjukkan bahwa pada sampel warna merah semakin tinggi konsentrasi warna maka intensitas $R$ akan semakin turun, hal ini juga berlaku untuk sampel warna biru. Hubungan antara konsentrasi warna dan nilai $R, G$, dan $B$ ditunjukkan pada Gambar 6 dan Gambar 7.

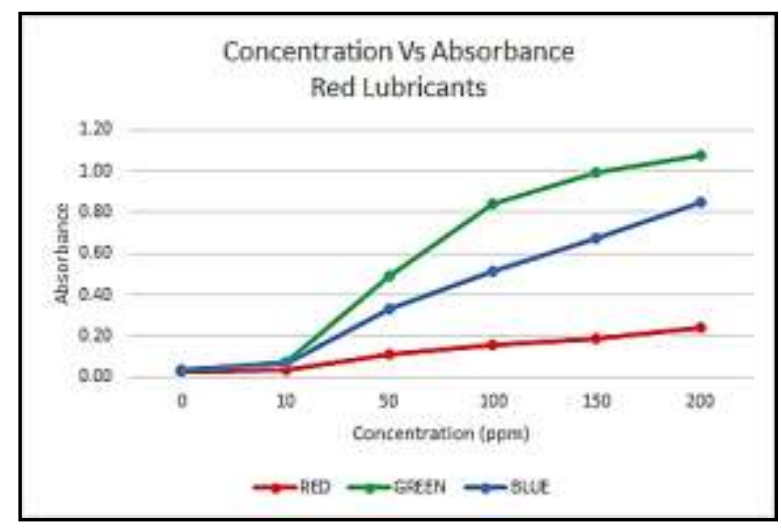

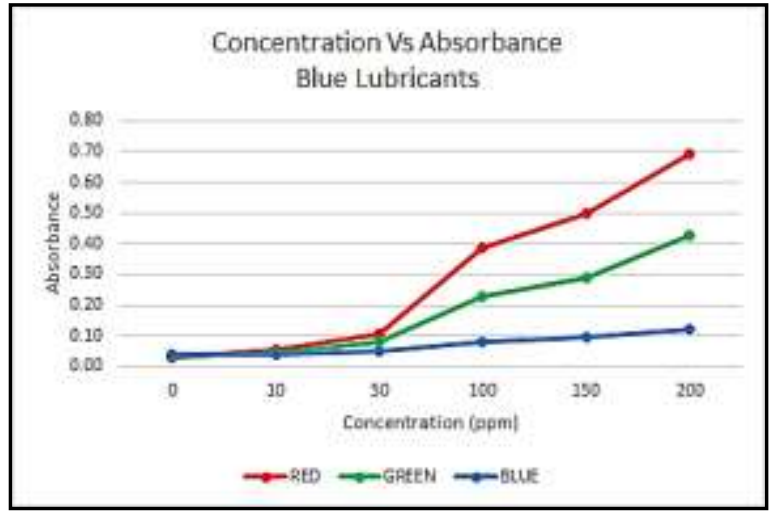

Gambar 7. Absorban pelumas warna biru

Apabila cahaya jatuh pada suatu medium homogen, sebagian dari sinar masuk akan sipantulkan, sebagian diserap dalam medium itu, dan sisanya diteruskan. Pada penelitian ini komposisi nilai $R, G$ dan $B$ diperoleh melalui cahaya yang dipantulkan oleh sampel dan ditangkap oleh kamera. Jika nilai $R, G, B$ latar diketahui, maka dapat dihitung nilai absorbans pada masing-masing sampel.

$$
A=\log \left(\frac{1}{R}\right) ; R=\frac{I}{I_{0}}
$$

Dengan $A$ absorbans, $R$ reflektans, $I$ intensitas sampel dan $I_{0}$ intensitas background. Berdasarkan grafik pada Gambar 6 dan Gambar 7, absorbans memiliki korelasi dengan konsentrasi, semakin tinggi konsentrasi, maka absorbans semakin tinggi juga. Pada sampel pelumas warna merah, absorbans hijau memiliki nilai yang paling tinggi dibandingkan dengan absorbans biru dan absorbans merah memiliki nilai yang paling rendah. Hal ini disebabkan oleh sampel pelumas berwarna merah ketika dikenai cahaya, detektor akan menangkap lebih besar cahaya yang dipantulkan berwarna merah, sehingga warna merah diserap paling sedikit. Pada sampel pelumas berwarna biru, absorbans merah memiliki nilai yang paling tinggi dibandingkan dengan absorbans hijau, dan absorbans biru paling rendah. Sampel pelumas berwarna biru lebih banyak memantulkan cahaya warna biru dan menyerap cahaya warna orange. Warna orange merupakan perpaduan antara warna merah dan warna kuning, oleh karena itu absorbans merah memiliki nilai tertinggi.

Data rerata nilai $R, G$, dan $B$ masing-masing sampel pelumas dibuat sebagai acuan dalam mengenali konsentrasi warna, namun pada penelitian ini data uji 
yang digunakan sama dengan sampel penelitian. Metode yang digunakan untuk mengenali data uji berdasarkan Persamaan 3.

$$
d r=R-G ; \quad d g=G-B ; \quad d b=B-R
$$

Variable $d r$ merupakan selisih antara rerata nilai $R$ dan $G, d g$ selisih rerata $G$ dan $B, d b$ selisih rerata nilai $B$ dan $R$. Algoritma program yang digunakan untuk mengenali konsentrasi dan warna pelumas ditunjukkan pada Gambar 8.

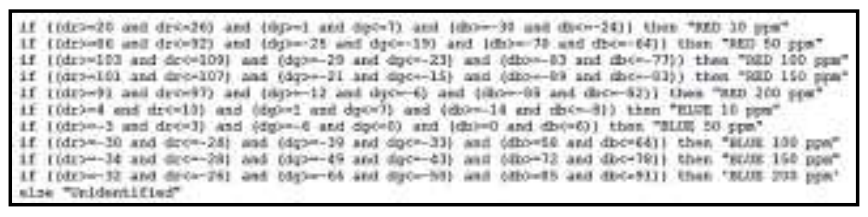

Gambar 7. Algoritma program

Prosedur dalam melakukan pengujian hampir sama pada proses pengambilan data, yaitu meletakkan sampel pelumas pada cuvette, kemudian mengambil gambar sampel pelumas melalui webcam, menghitung rerata nilai $R, G, B$ data uji. Kecocokan antara data uji dengan data sampel ditentukan oleh kesesuaian antara nilai $d r, d g$ dan $d b$. Hasil pengujian kecocokan antara data uji dengan sampel ditunjukkan pada Tabel 2.

TABEL 2

HASIL UJI KECOCOKAN ANTARA DATA UJI DENGAN SAMPEL

\begin{tabular}{|c|c|c|c|c|c|}
\hline No & R & G & B & Dikenali sebagai & Keterangan \\
\hline 1 & 38 & 64 & 125 & Blue $200 \mathrm{ppm}$ & Sesuai \\
\hline 2 & 119 & 18 & 34 & Red $150 \mathrm{ppm}$ & Sesuai \\
\hline 3 & 74 & 98 & 134 & Blue $100 \mathrm{ppm}$ & Sesuai \\
\hline 4 & 37 & 64 & 124 & Blue $200 \mathrm{ppm}$ & Sesuai \\
\hline 5 & 120 & 18 & 35 & Red $150 \mathrm{ppm}$ & Sesuai \\
\hline 6 & 73 & 98 & 133 & Blue $100 \mathrm{ppm}$ & Sesuai \\
\hline 7 & 139 & 53 & 74 & Red $50 \mathrm{ppm}$ & Sesuai \\
\hline 8 & 108 & 15 & 23 & Red $200 \mathrm{ppm}$ & Sesuai \\
\hline 9 & 152 & 144 & 141 & Blue $10 \mathrm{ppm}$ & Sesuai \\
\hline 10 & 141 & 54 & 75 & Red $50 \mathrm{ppm}$ & Sesuai \\
\hline 11 & 153 & 146 & 142 & Blue $10 \mathrm{ppm}$ & Sesuai \\
\hline 12 & 107 & 15 & 23 & Red $200 \mathrm{ppm}$ & Sesuai \\
\hline 13 & 128 & 25 & 50 & Red $100 \mathrm{ppm}$ & Sesuai \\
\hline 14 & 57 & 86 & 131 & Blue $150 \mathrm{ppm}$ & Sesuai \\
\hline 15 & 135 & 136 & 139 & Blue $50 \mathrm{ppm}$ & Sesuai \\
\hline 16 & 57 & 86 & 131 & Blue $150 \mathrm{ppm}$ & Sesuai \\
\hline 17 & 126 & 21 & 46 & Red $100 \mathrm{ppm}$ & Sesuai \\
\hline 18 & 135 & 136 & 138 & Blue $50 \mathrm{ppm}$ & Sesuai \\
\hline 19 & 164 & 139 & 135 & Red $10 \mathrm{ppm}$ & Sesuai \\
\hline 20 & 164 & 139 & 135 & Red $10 \mathrm{ppm}$ & Sesuai \\
\hline
\end{tabular}

Berdasarkan data percobaan pada Tabel 2 dapat dilihat bahwa sistem mampu mengenali pelumas berdasarkan konsentrasi dan warnanya $100 \%$ benar. Sistem ini dapat dikembangkan lebih lanjut sebagai metode untuk mengenali keaslian minyak pelumas.

\section{KESIMPULAN}

Dari penelitian yang sudah dilakukan, dapat disimpulkan bahwa:

1. Semakin tinggi konsentrasi warna merah yang ada didalam pelumas mengakibatkan nilai komponen Red $(R)$ dari citra semakin menurun nilainya, dapat diartikan bahwa tingkat warna merah semakin pekat. Demikian juga untuk pelumas dengan konsentrasi warna biru, semakin tinggi konsentrasi warna biru dalam pelumas mengakibatkan nilai komponen blue $(B)$ dari citra semakin turun atau dengan kata lain warna biru semakin pekat.

2. Sampel pelumas warna merah akan memantulkan lebih banyak cahaya merah dan menyerap cahaya biru, hal ini dibuktikan dengan absorbans tertinggi pada warna hijau dan absorbans terendah pada warna merah. Warna hijau merupakan komplemen warna merah demikian pula sebaliknya. Sedangkan, pada sampel pelumas warna biru lebih banyak memantulkan cahaya biru dan menyerap lebih banyak warna merah. Data penelitian menunjukkan bahwa absorbans warna merah paling tinggi dan absorbans biru paling rendah. Warna biru memiliki komplemen warna orange, dimana warna orange merupakan perpaduan antara warna merah dan kuning.

3. Komposisi warna $R, G$, dan $B$ dari masing-masing sampel pelumas dapat digunakan sebagai parameter untuk mengidentifikasi konsentrasi dan warna pelumas. Penelitian menunjukkan metode ini mampu mengenali pelumas dengan benar $(100 \%)$ konsentrasi dan warnanya. Sampel yang digunakan untuk uji dan pengambilan data menggunakan sampel yang sama.

\section{UCAPAN TERIMA KASIH}

Peneliti ingin mengucapkan terima kasih yang sebesar-besarnya kepada PT. Pertamina yang telah mendukung dalam pengadaan sampel pelumas.

\section{DAFTAR PUSTAKa}

[1] 2008, Separuh Oli yang Beredar di Indonesia Palsu, Republika, 4 September 2018, https://republika.co.id/berita/breakingnews/ekonomi/08/12/18/20950-separuh-oli-yang-beredardi-indonesia-palsu.

[2] Aji G. A., 2017, MIAP: Pemalsuan Produk Merambah Segmen Pelumas Otomotif, Otomotif, 4 September 2018, 
https://otomotif.tempo.co/read/1129765/lindungi-

konsumen-kemenperin-wajibkan-pelumas-berstandar-sni.

[3] ASTM International US, 2009, 'Standard Test Method for ASTM Color of Petroleum Products ( ASTM Color Scale ) 1', Annual Book of ASTM Standards: $1-5$.

[4] Basset, dkk., 1994, Vogel Text book of Kuantitatif Chemical Analisys fifth edition, London : the school of chemistry phemes politechnics.

[5] Darmanto, 2011, 'Mengenal Pelumas Pada Mesin', Momentum, Vol. 7 No. 1 April 2011: 5- 10.

[6] Mara I M., Kurniawan A., 2015, 'Analisa Pemurnian Minyak Pelumas Bekas dengan Metode Acid and Clay', Dinamika Teknik Mesin, Vol. 5 No. 2 Juli 2015: 106 - 112

[7] M. Arisandi, Darmanto, T. Priangkoso, 2012, 'Analisa Pengaruh Bahan Dasar Pelumas Terhadap Viskositas Pelumas Dan Konsumsi Bahan Bakar', Momentum, Vol. 8 No. 1 April 2012: 56- 61. 
Pengenalan Konsentrasi Warna Pelumas Menggunakan Webcam 